\title{
TiN film growth on misoriented TiN grains with simultaneous low-energy bombardment: Restructuring leading to epitaxy
}

Daniel Edström, Davide Sangiovanni, Lars Hultman, Ivan Petrov, Joseph E Greene and Valeriu Chirita

The self-archived postprint version of this journal article is available at Linköping University Institutional Repository (DiVA):

http://urn.kb.se/resolve?urn=urn:nbn:se:liu:diva-160969

N.B.: When citing this work, cite the original publication.

Edström, D., Sangiovanni, D., Hultman, L., Petrov, I., Greene, J. E, Chirita, V., (2019), TiN film growth on misoriented TiN grains with simultaneous low-energy bombardment: Restructuring leading to epitaxy, Thin Solid Films, 688, 137380. https://doi.org/10.1016/j.tsf.2019.06.030

Original publication available at:

https://doi.org/10.1016/j.tsf.2019.06.030

Copyright: Elsevier

http://www.elsevier.com/

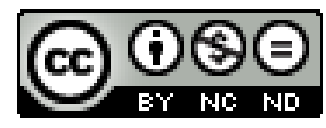


TiN film growth on misoriented TiN grains with simultaneous low-energy bombardment: restructuring leading to epitaxy

D. Edström, ${ }^{\mathrm{a}, b^{*}}$ D.G. Sangiovanni, ${ }^{\mathrm{a}, \mathrm{c}}$ L. Hultman, ${ }^{\mathrm{a}}$ I. Petrov, ${ }^{\mathrm{a}, \mathrm{d}}$ J.E. Greene, ${ }^{\mathrm{a}, \mathrm{d}}$ V. Chirita ${ }^{\mathrm{a}}$ ${ }^{a}$ Department of Physics, Chemistry, and Biology (IFM) Linköping University, SE-58183 Linköping, Sweden ${ }^{\mathrm{b} S}$ School of Science and Technology, Örebro University, SE-70182, Örebro, Sweden 'ICAMS, Ruhr-Universität Bochum, 44780 Bochum, Germany

${ }^{\mathrm{d}}$ Frederick Seitz Materials Research Laboratory and the Materials Science Department, University of Illinois at Urbana-Champaign, Urbana, Illinois 61801, USA

\begin{abstract}
We perform large-scale molecular dynamics simulations of TiN deposition at $1200 \mathrm{~K}$ on TiN substrates consisting of under-stoichiometric $(\mathrm{N} / \mathrm{Ti}=0.86)$ misoriented grains. The energy of incoming Ti atoms is $2 \mathrm{eV}$ and that of incoming $\mathrm{N}$ atoms is $10 \mathrm{eV}$. The simulations show that misoriented grains are reoriented during the early stages of growth, after which the film grows 001 epitaxially and is nearly stoichiometric. The grain reorientation coincides with an increase in film N/Ti ratio. As the grains reorient, additional nitrogen can no longer be accommodated, and the film composition becomes stoichiometric as the overlayer grows epitaxially.
\end{abstract}




\section{Introduction}

Transition-metal (TM) nitride [1-3] thin films are employed in a wide variety of applications due to their unique combination of properties including high hardness, [1,4-6] scratch and abrasion resistance, [7] low coefficient of friction, [8] high-temperature oxidation resistance, [9-11] metallic-to-semiconducting electrical conductivity, [12-15] optical absorption which is tunable across the visible spectrum, [16,17] biocompatibility, [18] and superconductivity. $[12,19,20] \mathrm{TiN}_{\mathrm{x}}$, with a single-phase field ranging from $\mathrm{x}=0.6$ to $1.0,[21]$ was one of the first hard-coating materials and today serves as a model system for investigating NaCl-structure TM nitride compounds and alloys. Consequently, TiN has been extensively studied experimentally in order to probe nucleation and island formation, [22,23] growth kinetics, [24-27] and microstructure and texture evolution. [28-40]

Fundamental understanding of the processes governing nanostructural and surface morphological evolution during thin-film growth requires detailed information regarding the dynamics of mass transport on surfaces, nucleation, and the early stages of growth. Since surface processes occurring on the picosecond time scale cannot be resolved with state-of-theart atomic-scale experimental techniques, such as scanning tunneling microscopy [24,25,41] and low-energy electron microscopy, [42] the use of complementary computational investigations is essential. Conversely, while ab-initio computational methods such as density functional theory (DFT) have been successfully applied in studies of materials properties $[43,44]$ and fundamental surface interactions, [45] the system sizes and time scales required for film-growth studies are prohibitively large for these methods. This renders methods such as Kinetic Monte Carlo (KMC) [46] and Classical Molecular Dynamics (CMD) $[47,48]$ as the primary computational tool for large-scale studies of film growth dynamics.

We have previously applied CMD to investigate both intralayer and interlayer mass transport of Ti and $\mathrm{N}$ adatoms, and $\mathrm{TiN}_{\mathrm{x}}$ admolecules, on $\mathrm{TiN}(001)$ [49] and $\mathrm{TiN}(111)$ terraces 
[50] as well as on TiN/TiN(001) islands. [51,52] Ti adatom migration velocities on infinite terraces at $1000 \mathrm{~K}$ are nearly three times that of $\mathrm{N}$ adatoms [49]. On TiN/TiN(001) islands, $\mathrm{Ti}$ adatoms rapidly reach island step edges and descend exclusively via push-out/exchange processes, whereas $\mathrm{N}$ adatoms have lower mobilities and descend by both hopping over stepedges and push-out/exchange with $\mathrm{N}$ edge atoms. [51] Admolecule surface mobilities depend strongly on the $\mathrm{N}$-content of the molecule. While $\mathrm{TiN}_{2}$ admolecules display remarkably high mobilities on both flat $\mathrm{TiN}(001)$ terraces and $\mathrm{TiN} / \mathrm{TiN}(001)$ islands, $\mathrm{TiN}_{3}$ admolecules remain essentially stationary. Motivated by these results, we performed a large-scale MD study of TiN/TiN(001) film growth using incident $\mathrm{N} / \mathrm{Ti}$ ratios of $\mathrm{N} / \mathrm{Ti}=1,2$, and 4 to investigate the effect of the N/Ti ratio on film growth modes at $1200 \mathrm{~K}$ [53], a typical TiN/TiN(001) epitaxial growth temperature. [14,54] The results demonstrated that at low N/Ti flux ratios, both 100and 110-bounded epitaxial islands are formed, and surface roughening occurs through nucleation of 111 islands in areas of local $\mathrm{N}$ deficiency via growth of 110-oriented in-plane ladder-like structures. At higher N/Ti ratios, islands with N-terminated 110 edges become dominant and surface roughening occurs due to enhanced upper-layer nucleation. Films grown with $\mathrm{N} / \mathrm{Ti}=2$ display the smoothest surfaces.

The reaction paths of incident $\mathrm{N}$ and $\mathrm{Ti}$ atoms on $\mathrm{TiN}(001)$ surfaces have been theoretically and experimentally shown to depend strongly on the incident kinetic energy $[47,54]$. The effect of the choice of incident energy was probed in a separate CMD study [55] in which TiN/TiN(001) films were grown at $1200 \mathrm{~K}$ using incident $\mathrm{N}$ energies $\mathrm{E}_{\mathrm{N}}$ of 2 and 10 $\mathrm{eV}$ at a flux ratio of $\mathrm{N} / \mathrm{Ti}=4$. The results showed that growth with $\mathrm{E}_{\mathrm{N}}=2 \mathrm{eV}$ results in globally overstoichiometric films with islands primarily bounded by N-terminated 110 edges; rapid upper-layer nucleation led to surface roughening. With $\mathrm{E}_{\mathrm{N}}=10 \mathrm{eV}$, small islands were continuously dissociated into smaller clusters and adatoms leading to higher upper-layer 
supersaturation, resulting in smoother films with compositions close to stoichiometric. Incident energetic $\mathrm{N}$ atoms also give rise to increased nitrogen desorption and reflection.

The large-scale CMD studies described above were designed to investigate the initial stages of growth, up to coverages of 0.85 and 1.5 monolayers, respectively. In both cases, the films were grown on perfectly smooth stoichiometric TiN(001) substrates. In this study, we investigate mechanisms by which low-energy ion irradiation affects TiN growth on a non-flat TiN substrate with misoriented grains. Using incident energies $\mathrm{E}_{\mathrm{N}}=10 \mathrm{eV}$ and $\mathrm{E}_{\mathrm{Ti}}=2 \mathrm{eV}$, we simulate the growth of several monolayers of TiN. The results show that the initially misoriented grains are quickly restructured as energetic nitrogen is deposited; the resulting film is epitaxial.

\section{Methodology}

We perform large-scale CMD simulations of TiN/TiN(001) film growth at $1200 \mathrm{~K}$, a temperature within the optimal range for $\mathrm{TiN}(001)$ epitaxial growth $[14,54]$ with a N/Ti flux ratio of six and incident $\mathrm{Ti}$ and $\mathrm{N}$ energies of 2 and $10 \mathrm{eV}$, respectively. An energy of $2 \mathrm{eV}$ corresponds approximately to thermal atoms accelerated by the surface potential of the substrate. [56] During dc magnetron sputter deposition of TiN in pure $\mathrm{N}_{2}, \sim 96 \%$ of all incident ions are $\mathrm{N}_{2}{ }^{+}$ions. With a typical floating potential of $-20 \mathrm{~V}$, the energy per atom upon dissociative impact will be $10 \mathrm{eV}$. [56] In previous MD studies, the use of $\mathrm{N}$ atoms incident at $10 \mathrm{eV}$ energies resulted in smoother films, compared to $2 \mathrm{eV} \mathrm{N}$, and compositions near stoichiometric. [55]

The simulations are carried out using the modified embedded-atom method (MEAM) [57] interatomic potential as implemented in the Large-scale Atomic/Molecular Massively Parallel Simulator (LAMMPS) [58] with the TiN parameterization employed in references $[49,51,52,59,60]$. The parameterization has been validated using DFT-based ab-initio 
molecular dynamics to determine Ti [59] and $\mathrm{N}$ [60] diffusion kinetics on, as well as $\mathrm{N}_{2}$ desorption from, [60] $\mathrm{TiN}(001)$ surfaces.

We use the film grown on an ideal NaCl-structure TiN(001) substrate consisting of 100 x $100 \times 6$ atoms with a nearest-neighbor interatomic stance of $2.121 \AA$, corresponding to a lattice constant of $4.242 \AA$, with $\mathrm{E}_{\mathrm{Ti}}=\mathrm{E}_{\mathrm{N}}=2 \mathrm{eV}$ and N/Ti$=1$ at $1200 \mathrm{~K}$ in the study detailed in our previous work [53] as the starting surface. The present substrate contains 67,018 atoms with an average grain size of $580 \AA^{2}$. The N/Ti ratio at the substrate surface is 0.86 , in which an atom is considered part of the surface if its $\mathrm{z}$-coordinate is greater or equal to that of the top surface layer. An atomic-scale plan-view of the present substrate is shown in Figure 1. The misoriented grains (primarily 111), with a coverage of $0.18 \mathrm{ML}$ are smaller than the 100oriented grains, with an average grain size of $430 \AA^{2}$ compared to $760 \AA^{2}$ for 100 -oriented grains.

The total simulation cell size is $212.1 \times 212.1 \times 65.6 \AA$, periodic boundary conditions are applied in the in-plane directions, and the simulation timesteps are 1 fs. Atoms in the bottom substrate layer are stationary, while atoms in the second, third, and fourth lowest layers are subject to velocity rescaling at each time-step and thus act as a heat sink to maintain the temperature constant at $1200 \mathrm{~K}$. Atoms in the third layer and above, are free of any constraints. Every 100 timesteps, or $0.1 \mathrm{ps,}$ we add a Ti atom and $6 \mathrm{~N}$ atoms, starting at random positions within $2 \AA$ from the top of the simulation box, which corresponds to approximately $43 \AA$ above the topmost substrate atom at the start of the simulation. The incident atoms are assigned a random velocity within a $30^{\circ}$ angle from normal incidence corresponding to an average energy of $2 \mathrm{eV}$ for $\mathrm{Ti}$ and $10 \mathrm{eV}$ for $\mathrm{N}$ atoms. The range of incidence angles is used to approximate TiN deposition by magnetron sputtering, for which atoms are sputtered with a cosine distribution followed by ballistic transport through the gas phase. [61] 
The coordinates of atoms belonging to the sixth layer and above are stored every 1,000 timesteps (1 ps) in MD videos which are visualized using Visual Molecular Dynamics. [62] In addition, the coordinates of all atoms in the simulation are stored every 150,000 timesteps (150 ps). We simulate $\tau=5.25 \mathrm{~ns}$ of deposition time in which 52,500 $\mathrm{Ti}$ atoms are incident at the substrate and growing film. This corresponds, for unity $\mathrm{Ti}$ incorporation probability, to a nominal Ti sublattice coverage of 10.5 ML. Due to losses associated with incident-atom reflection and desorption, the actual final sublattice coverage is $9.81 \mathrm{ML}$, which corresponds to a growth rate of $1.87 \mathrm{ML} / \mathrm{ns}$. During the initial $0.6 \mathrm{~ns}$ deposition time, we store the coordinates of all atoms every $25 \mathrm{fs}$ in order to obtain a more detailed view of the initial growth stages. Atoms are free to leave the simulation box via direct reflection or through $\mathrm{N}_{2}$ desorption as $\mathrm{N}$ adatoms bond with, and remove, $\mathrm{N}$ surface atoms. $[47,60]$

\section{Results and Discussion}

Figure 2 is a plot of the number of $\mathrm{Ti}$ and $\mathrm{N}$ atoms accommodated in the growing film (sixth layer and above), as a function of film coverage. Atoms in the fifth layer and below are considered part of the substrate. The corresponding film stoichiometry (N/Ti ratio) is also plotted on the right vertical axis. At the onset of deposition, the growing film is understoichiometric $(\mathrm{N} / \mathrm{Ti} \approx 0.84)$ due to the low $\mathrm{N} / \mathrm{Ti}$ ratio in the substrate [53], $\mathrm{TiN}_{0.84}$. During film growth with $\mathrm{N} / \mathrm{Ti}=6$, the film quickly becomes overstoichiometric, due to adsorption of $\mathrm{N}$ adatoms and formation of $\mathrm{N}$-rich admolecules on the film surface, with a maximum N/Ti $=$ 1.12 after deposition of 1.4 ML. As deposition continues, the film stoichiometry stabilizes at $\operatorname{TiN}_{1.05}$.

Film growth on misoriented grains present in the initial substrate leads to mound formation, in contrast to the flat epitaxial islands which form on 100-oriented grains. However, the misoriented grains are eliminated during the early stages of deposition. Figure 3 shows the 
evolution, in both plan view and cross-section, of the typical misoriented grain highlighted in Figure 1 during the initial $0.6 \mathrm{~ns}$ of deposition. The outline of the original misoriented grain is highlighted in white for each cross-section. In cross-sections (a)-(c), the grain boundary is highlighted in cyan. After reaching a coverage $\theta$ of $0.61 \mathrm{ML}$, the misoriented grain is still present, but noticeably smaller. At $\theta=0.81 \mathrm{ML}$, the grain size is significantly reduced. Interestingly, the reorientation does not appear to proceed from the top of the grain and into the film, but instead proceeds from within the grain toward the surface. The grain is completely reoriented to 001 at $\theta=1.13 \mathrm{ML}$. Following deposition of $1.43 \mathrm{ML}$, the grain was allowed to relax for $0.15 \mathrm{~ns}$ without further deposition and it was found to remain stable in the 001 configuration. For completeness, we also show three snapshots of the film in the later stages of deposition. Figures 3(h)-(i), corresponding to $\theta=3.04,5.74$, and 9.81 ML, are cross-sections of the 001 layers grown on the initially misoriented 111 grain. Note the apparent formation of a pore in Fig. 3(i). Such pores are formed during film growth when two separate growing layers converge, giving the impression of a pore, which is filled as mobile Ti adatoms descend from upper layers.

To quantify the grain reorientation, we count the number of Ti film atoms in epitaxial positions according to the following method. We define a grid of ideal epitaxial positions with an inter-site distance $\mathrm{d}_{\mathrm{NN}}=2.121 \AA$ along in-plane directions. For each as-deposited Ti atom, we identify the closest ideal epitaxial site and calculate the distance. If the square of the distance exceeds $0.06 \mathrm{~d}_{\mathrm{NN}}^{2}$, the atom is considered in a non-epitaxial site; otherwise it is epitaxial.

The overall results of this analysis are plotted in Fig. 4 as the fraction of non-epitaxial film atoms vs total film coverage $\theta$. Initially, there is a slight increase in the fraction of nonepitaxial atoms, as recently-deposited Ti atoms have yet to reach stable positions. In addition, isolated Ti adatoms on $\mathrm{TiN}(001)$ are known to favor fourfold-hollow sites over epitaxial sites. $[49,59]$ The non-epitaxial fraction reaches a maximum at $\theta \simeq 0.10 \mathrm{ML}$, after which it decreases 
throughout the remainder of film deposition and saturates at $\theta \simeq 0.01$. The non-epitaxial fraction does not reach zero since atoms are being deposited continuously. This demonstrates quantitively that the misoriented grains present in the initial substrate, which formed during growth with thermal species, are reoriented, leading to epitaxial TiN overgrowth, during energetic deposition.

The mechanism of the grain reorientation is similar to that of grain growth driven by total grain-boundary minimization. The lower-surface-energy [63] 001-oriented grain consumes the misoriented grain, thus eliminating the boundary and decreasing the total surface energy. The probability of atoms crossing the grain-boundary is facilitated by increased lattice vibrations due to energetic $\mathrm{N}$ impact.

We note that the deposited coverage required for grain reorientation, 1.43 ML, matches that of the initial increase in film N/Ti ratio to the maximum value (Fig. 2). The misoriented grains, which are understoichiometric, consume the excess nitrogen. When the grains are completely reoriented, the film can no longer accommodate excess nitrogen and the N/Ti ratio stabilizes at a value which is essentially stoichiometric.

\section{Conclusions}

We have performed large-scale molecular dynamics simulations of TiN thin film deposition at $1200 \mathrm{~K}$ on $\mathrm{TiN}$ substrates consisting of under-stoichiometric misoriented (primarily 111) grains. The N/Ti growth flux ratio is six with incident $\mathrm{Ti}$ and $\mathrm{N}$ energies of 2 and $10 \mathrm{eV}$, respectively. The results show that the substrates grains are quickly reoriented to 001 during the very early stages of deposition and the film proceeds to grow with an $(001) /[100]$ epitaxial relationship to the substrate. The reorientation coincides with an increase in the film $\mathrm{N} / \mathrm{Ti}$ ratio. When the film/substrate system is fully reoriented, the film can no longer 
accommodate additional nitrogen and the film $\mathrm{N} / \mathrm{Ti}$ ratio stabilizes at a value close to stoichiometry, $\mathrm{TiN}_{1.05}$, as the film continues to grow epitaxially.

\section{Acknowledgements}

Calculations were performed using resources provided by the Swedish National Infrastructure for Computing (SNIC), on the Kappa and Triolith Clusters located at the National Supercomputer Centre (NSC) at Linköping University. We also appreciate the financial support from the Swedish Research Council (VR) Linköping Linnaeus Initiative LiLi-NFM (grant 2008-6572) and Project Grants 2009-00971, 2013-4018, and 2014-5790; the Swedish Government Strategic Research Area Grant in Materials Science on Advanced Functional Materials; and the Knut and Alice Wallenberg Foundation (2011-KAW Scholar and Isotope Project). D.G.S. gratefully acknowledges financial support from the Olle Engkvist Foundation and the competence center FunMat-II that is supported by Vinnova (grant 2016-05156). 


\section{References}

[1] H. Ljungcrantz, M. Odén, L. Hultman, J.E. Greene, J.-E. Sundgren, Nanoindentation studies of single-crystal (001)-, (011)-, and (111)-oriented TiN layers on MgO, J. Appl. Phys. 80 (1996) 6725. doi:10.1063/1.363799.

[2] J.-E. Sundgren, Structure and properties of TiN coatings, Thin Solid Films. 128 (1985) 21-44. doi:10.1016/0040-6090(85)90333-5.

[3] J.E. Greene, J.-E. Sundgren, L. Hultman, I. Petrov, D.B. Bergstrom, Development of preferred orientation in polycrystalline TiN layers grown by ultrahigh vacuum reactive magnetron sputtering, Appl. Phys. Lett. 67 (1995) 2928. doi:10.1063/1.114845.

[4] T. Reeswinkel, D.G. Sangiovanni, V. Chirita, L. Hultman, J.M. Schneider, Structure and mechanical properties of TiAIN-WN $\mathrm{W}_{\mathrm{x}}$ thin films, Surf. Coat. Technol. 205 (2011) 4821-4827. doi:10.1016/j.surfcoat.2011.04.066.

[5] C.-S. Shin, D. Gall, N. Hellgren, J. Patscheider, I. Petrov, J.E. Greene, Vacancy hardening in singlecrystal TiN $\mathrm{T}_{\mathrm{x}}(001)$ layers, J. Appl. Phys. 93 (2003) 6025-6028. doi:10.1063/1.1568521.

[6] H. Kindlund, D.G. Sangiovanni, J. Lu, J. Jensen, V. Chirita, I. Petrov, J.E. Greene, L. Hultman, Effect of $\mathrm{WN}$ content on toughness enhancement in $\mathrm{V}_{1-\mathrm{x}} \mathrm{W}_{\mathrm{x}} \mathrm{N} / \mathrm{MgO}(001)$ thin films, J. Vac. Sci. Technol. Vac. Surf. Films. 32 (2014) 030603. doi:10.1116/1.4867610.

[7] P. Hedenqvist, M. Bromark, M. Olsson, S. Hogmark, E. Bergmann, Mechanical and tribological characterization of low-temperature deposited PVD TiN coatings, Surf. Coat. Technol. 63 (1994) 115-122. doi:10.1016/S0257-8972(05)80015-5.

[8] T. Polcar, T. Kubart, R. Novák, L. Kopecký, P. Široký, Comparison of tribological behaviour of TiN, TiCN and CrN at elevated temperatures, Surf. Coat. Technol. 193 (2005) 192-199. doi:10.1016/j.surfcoat.2004.07.098.

[9] A.S. Ingason, F. Magnus, J.S. Agustsson, S. Olafsson, J.T. Gudmundsson, In-situ electrical characterization of ultrathin TiN films grown by reactive dc magnetron sputtering on SiO2, Thin Solid Films. 517 (2009) 6731-6736. doi:10.1016/j.tsf.2009.05.028.

[10] D. McIntyre, J.E. Greene, G. Håkansson, J.-E. Sundgren, W.-D. Münz, Oxidation of metastable single-phase polycrystalline Ti0.5AI0.5N films: Kinetics and mechanisms, J. Appl. Phys. 67 (1990) 1542-1553. doi:10.1063/1.345664.

[11] L.A. Donohue, I.J. Smith, W.-D. Münz, I. Petrov, J.E. Greene, Microstructure and oxidationresistance of $\mathrm{Ti}_{1-x-y-z} \mathrm{Al}_{x} \mathrm{Cr}_{y} \mathrm{Y}_{z} \mathrm{~N}$ layers grown by combined steered-arc/unbalanced-magnetronsputter deposition, Surf. Coat. Technol. 94-95 (1997) 226-231. doi:10.1016/S02578972(97)00249-1.

[12] A.B. Mei, A. Rockett, L. Hultman, I. Petrov, J.E. Greene, Electron/phonon coupling in group-IV transition-metal and rare-earth nitrides, J. Appl. Phys. 114 (2013) 193708. doi:10.1063/1.4832778.

[13] H.-S. Seo, T.-Y. Lee, J.G. Wen, I. Petrov, J.E. Greene, D. Gall, Growth and physical properties of epitaxial HfN layers on MgO(001), J. Appl. Phys. 96 (2004) 878-884. doi:10.1063/1.1759783.

[14] C.-S. Shin, S. Rudenja, D. Gall, N. Hellgren, T.-Y. Lee, I. Petrov, J.E. Greene, Growth, surface morphology, and electrical resistivity of fully strained substoichiometric epitaxial $\operatorname{TiNx}(0.67 \leqslant x<1.0)$ layers on MgO(001), J. Appl. Phys. 95 (2004) 356-362. doi:10.1063/1.1629155.

[15] D. Gall, I. Petrov, N. Hellgren, L. Hultman, J.E. Sundgren, J.E. Greene, Growth of poly- and singlecrystal ScN on $\mathrm{MgO}(001)$ : Role of low-energy $\mathrm{N}_{2}{ }^{+}$irradiation in determining texture, microstructure evolution, and mechanical properties, J. Appl. Phys. 84 (1998) 6034-6041. doi:10.1063/1.368913.

[16] D. Gall, I. Petrov, J.E. Greene, Epitaxial $\mathrm{Sc}_{1-\mathrm{x}} \mathrm{Ti} \times \mathrm{N}(001)$ : Optical and electronic transport properties, J. Appl. Phys. 89 (2001) 401-409. doi:10.1063/1.1329348.

[17] P. Patsalas, N. Kalfagiannis, S. Kassavetis, Optical Properties and Plasmonic Performance of Titanium Nitride, Materials. 8 (2015) 3128-3154. doi:10.3390/ma8063128. 
[18] W.-Y. Wu, M.-Y. Chan, Y.-H. Hsu, G.-Z. Chen, S.-C. Liao, C.-H. Lee, P.-W. Lui, Bioapplication of TiN thin films deposited using high power impulse magnetron sputtering, Surf. Coat. Technol. 362 (2019) 167-175. doi:10.1016/j.surfcoat.2019.01.106.

[19] H.-S. Seo, T.-Y. Lee, I. Petrov, J.E. Greene, D. Gall, Epitaxial and polycrystalline $H f N x(0.8 \leqslant x \leqslant 1.5)$ layers on $\mathrm{MgO}(001)$ : Film growth and physical properties, J. Appl. Phys. 97 (2005) 083521. doi:10.1063/1.1870097.

[20] C.-S. Shin, D. Gall, Y.-W. Kim, P. Desjardins, I. Petrov, J.E. Greene, M. Odén, L. Hultman, Epitaxial $\mathrm{NaCl}$ structure $\delta-\mathrm{TaNx}(001)$ : Electronic transport properties, elastic modulus, and hardness versus N/Ta ratio, J. Appl. Phys. 90 (2001) 2879-2885. doi:10.1063/1.1391214.

[21] J.E. Sundgren, B.O. Johansson, A. Rockett, S.A. Barnett, J.E. Greene, TiN: A Review of the Present Understanding of the Atomic and Electronic Structure and Recent Results on the Growth and Physical Properties of Epitaxial TiNx $(0.6<x<1.2)$ Layers, in: J.E. Greene, W.D. Sproul, J.A. Thornton (Eds.), Physics and Chemistry of Protective Coatings, American Institute of Physics, New York, NY, 1986.

[22] M.A. Wall, D.G. Cahill, I. Petrov, D. Gall, J.E. Greene, Nucleation kinetics during homoepitaxial growth of TiN(001) by reactive magnetron sputtering, Phys. Rev. B. 70 (2004) 035413. doi:10.1103/PhysRevB.70.035413.

[23] M.A. Wall, D.G. Cahill, I. Petrov, D. Gall, J.E. Greene, Nucleation kinetics versus nitrogen partial pressure during homoepitaxial growth of stoichiometric TiN(0 01$)$ : A scanning tunneling microscopy study, Surf. Sci. 581 (2005) L122-127. doi:10.1016/j.susc.2005.03.007.

[24] S. Kodambaka, V. Petrova, A. Vailionis, P. Desjardins, D.G. Cahill, I. Petrov, J.E. Greene, TiN(001) and TiN(111) island coarsening kinetics: in-situ scanning tunneling microscopy studies, Thin Solid Films. 392 (2001) 164-168. doi:10.1016/S0040-6090(01)01022-7.

[25] S. Kodambaka, V. Petrova, A. Vailionis, I. Petrov, J.E. Greene, In situ high-temperature scanning tunneling microscopy studies of two-dimensional TiN island coarsening kinetics on TiN(0 011$)$, Surf. Sci. 526 (2003) 85-96. doi:10.1016/S0039-6028(02)02570-0.

[26] F.H. Baumann, D. I. Chopp, T.D. de la Rubia, G.E. Gilmer, J.E. Greene, H. Huang, S. Kodambaka, P. O'Sullivan, I. Petrov, Multiscale Modeling of Thin-Film Deposition: Applications to Si Device Processing, MRS Bull. 26 (2001) 182-189. doi:10.1557/mrs2001.40.

[27] S. Kodambaka, S.V. Khare, V. Petrova, A. Vailionis, I. Petrov, J.E. Greene, Absolute orientationdependent TiN(0 01 1) step energies from two-dimensional equilibrium island shape and coarsening measurements on epitaxial TiN(0 0 1) layers, Surf. Sci. 513 (2002) 468-474. doi:10.1016/S0039-6028(02)01845-9.

[28] C.-S. Shin, D. Gall, Y.-W. Kim, N. Hellgren, I. Petrov, J.E. Greene, Development of preferred orientation in polycrystalline $\mathrm{NaCl}$-structure $\delta$-TaN layers grown by reactive magnetron sputtering: Role of low-energy ion surface interactions, J. Appl. Phys. 92 (2002) 5084-5093. doi:10.1063/1.1510558.

[29] U. Helmersson, J.-E. Sundgren, J.E. Greene, Microstructure evolution in TiN films reactively sputter deposited on multiphase substrates, J. Vac. Sci. Technol. A. 4 (1986) 500-503. doi:10.1116/1.573868.

[30] B.W. Karr, I. Petrov, D.G. Cahill, J.E. Greene, Morphology of epitaxial TiN(001) grown by magnetron sputtering, Appl. Phys. Lett. 70 (1997) 1703-1705. doi:10.1063/1.118675.

[31] Z. Xu, Z. Zhang, M. Bartosik, Y. Zhang, P.H. Mayrhofer, Y. He, Insight into the structural evolution during TiN film growth via atomic resolution TEM, J. Alloys Compd. 754 (2018) 257267. doi:10.1016/j.jallcom.2018.04.268.

[32] G. Abadias, Stress and preferred orientation in nitride-based PVD coatings, Surf. Coat. Technol. 202 (2008) 2223-2235. doi:10.1016/j.surfcoat.2007.08.029.

[33] S. Mahieu, D. Depla, Reactive sputter deposition of TiN layers: modelling the growth by characterization of particle fluxes towards the substrate, J. Phys. Appl. Phys. 42 (2009) 053002. doi:10.1088/0022-3727/42/5/053002. 
[34] J.P. Zhao, X. Wang, Z.Y. Chen, S.Q. Yang, T.S. Shi, X.H. Liu, Overall energy model for preferred growth of TiN films during filtered arc deposition, J. Phys. Appl. Phys. 30 (1997) 5-12. doi:10.1088/0022-3727/30/1/002.

[35] G. Abadias, W.P. Leroy, S. Mahieu, D. Depla, Influence of particle and energy flux on stress and texture development in magnetron sputtered TiN films, J. Phys. Appl. Phys. 46 (2013) 055301. doi:10.1088/0022-3727/46/5/055301.

[36] F. Cemin, G. Abadias, T. Minea, D. Lundin, Tuning high power impulse magnetron sputtering discharge and substrate bias conditions to reduce the intrinsic stress of TiN thin films, Thin Solid Films. (2019). doi:10.1016/j.tsf.2019.05.054.

[37] R. Machunze, A.P. Ehiasarian, F.D. Tichelaar, G.C.A.M. Janssen, Stress and texture in HIPIMS TiN thin films, Thin Solid Films. 518 (2009) 1561-1565. doi:10.1016/j.tsf.2009.09.069.

[38] G. Abadias, Y.Y. Tse, Ph. Guérin, V. Pelosin, Interdependence between stress, preferred orientation, and surface morphology of nanocrystalline TiN thin films deposited by dual ion beam sputtering, J. Appl. Phys. 99 (2006) 113519. doi:10.1063/1.2197287.

[39] P. Patsalas, C. Gravalidis, S. Logothetidis, Surface kinetics and subplantation phenomena affecting the texture, morphology, stress, and growth evolution of titanium nitride films, J. Appl. Phys. 96 (2004) 6234-6246. doi:10.1063/1.1811389.

[40] A.P. Ehiasarian, A. Vetushka, Y.A. Gonzalvo, G. Sáfrán, L. Székely, P.B. Barna, Influence of high power impulse magnetron sputtering plasma ionization on the microstructure of TiN thin films, J. Appl. Phys. 109 (2011) 104314. doi:10.1063/1.3579443.

[41] S. Kodambaka, V. Petrova, A. Vailionis, P. Desjardins, D.G. Cahill, I. Petrov, J.E. Greene, In-situ high-temperature scanning-tunneling-microscopy studies of two-dimensional island-decay kinetics on atomically smooth TiN(001), Surf. Rev. Lett. 07 (2000) 589-593. doi:10.1142/S0218625X00000816.

[42] F. Watanabe, S. Kodambaka, W. Swiech, J.E. Greene, D.G. Cahill, LEEM study of island decay on Si(1 1 0), Surf. Sci. 572 (2004) 425-432. doi:10.1016/j.susc.2004.09.014.

[43] D. Holec, L. Zhou, H. Riedl, C.M. Koller, P.H. Mayrhofer, M. Friák, M. Šob, F. Körmann, J. Neugebauer, D. Music, M.A. Hartmann, F.D. Fischer, Atomistic Modeling-Based Design of Novel Materials: Atomistic Modeling-Based Design of Novel Materials, Adv. Eng. Mater. 19 (2017) 1600688. doi:10.1002/adem.201600688.

[44] M. to Baben, M. Hans, D. Primetzhofer, S. Evertz, H. Ruess, J.M. Schneider, Unprecedented thermal stability of inherently metastable titanium aluminum nitride by point defect engineering, Mater. Res. Lett. (2016) 1-12. doi:10.1080/21663831.2016.1233914.

[45] D. Music, J.M. Schneider, $A b$ initio study of $\mathrm{Ti}_{0.5} \mathrm{Al}_{0.5} \mathrm{~N}(001)$-residual and environmental gas interactions, New J. Phys. 15 (2013) 073004. doi:10.1088/1367-2630/15/7/073004.

[46] F. Nita, C. Mastail, G. Abadias, Three-dimensional kinetic Monte Carlo simulations of cubic transition metal nitride thin film growth, Phys. Rev. B. 93 (2016). doi:10.1103/PhysRevB.93.064107.

[47] Z. Xu, Q. Zeng, L. Yuan, Y. Qin, M. Chen, D. Shan, Molecular dynamics study of the interactions of incident N or Ti atoms with the TiN(001) surface, Appl. Surf. Sci. 360, Part B (2016) 946-952. doi:10.1016/j.apsusc.2015.11.090.

[48] Z.H. Xu, L. Yuan, D.B. Shan, B. Guo, A molecular dynamics simulation of TiN film growth on TiN(001), Comput. Mater. Sci. 50 (2011) 1432-1436. doi:10.1016/j.commatsci.2010.11.030.

[49] D.G. Sangiovanni, D. Edström, L. Hultman, V. Chirita, I. Petrov, J.E. Greene, Dynamics of Ti, N, and TiNx ( $x=1-3)$ admolecule transport on TiN(001) surfaces, Phys. Rev. B. 86 (2012) 155443. doi:10.1103/PhysRevB.86.155443.

[50] D.G. Sangiovanni, F. Tasnádi, L. Hultman, I. Petrov, J.E. Greene, V. Chirita, N and Ti adatom dynamics on stoichiometric polar TiN(111) surfaces, Surf. Sci. 649 (2016) 72-79. doi:10.1016/j.susc.2016.01.031.

[51] D. Edström, D.G. Sangiovanni, L. Hultman, V. Chirita, I. Petrov, J.E. Greene, Ti and N adatom descent pathways to the terrace from atop two-dimensional TiN/TiN(001) islands, Thin Solid Films. 558 (2014) 37-46. doi:10.1016/j.tsf.2014.02.053. 
[52] D. Edström, D.G. Sangiovanni, L. Hultman, I. Petrov, J.E. Greene, V. Chirita, The dynamics of TiNx $(x=1-3)$ admolecule interlayer and intralayer transport on TiN/TiN(001) islands, Thin Solid Films. 589 (2015) 133-144. doi:10.1016/j.tsf.2015.05.013.

[53] D. Edström, D.G. Sangiovanni, L. Hultman, I. Petrov, J.E. Greene, V. Chirita, Large-scale molecular dynamics simulations of TiN/TiN(001) epitaxial film growth, J. Vac. Sci. Technol. Vac. Surf. Films. 34 (2016) 041509. doi:10.1116/1.4953404.

[54] L. Hultman, S.A. Barnett, J.-E. Sundgren, J.E. Greene, Growth of epitaxial TiN films deposited on $\mathrm{MgO}(100)$ by reactive magnetron sputtering: The role of low-energy ion irradiation during deposition, J. Cryst. Growth. 92 (1988) 639-656. doi:10.1016/0022-0248(88)90048-6.

[55] D. Edström, D.G. Sangiovanni, L. Hultman, I. Petrov, J.E. Greene, V. Chirita, Effects of incident N atom kinetic energy on TiN/TiN(001) film growth dynamics: A molecular dynamics investigation, J. Appl. Phys. 121 (2017) 025302. doi:10.1063/1.4972963.

[56] I. Petrov, A. Myers, J.E. Greene, J.R. Abelson, Mass and energy resolved detection of ions and neutral sputtered species incident at the substrate during reactive magnetron sputtering of $\mathrm{Ti}$ in mixed $\mathrm{Ar}+\mathrm{N}_{2}$ mixtures, J. Vac. Sci. Technol. Vac. Surf. Films. 12 (1994) 2846. doi:10.1116/1.578955.

[57] B.-J. Lee, M.I. Baskes, Second nearest-neighbor modified embedded-atom-method potential, Phys. Rev. B. 62 (2000) 8564-8567. doi:10.1103/PhysRevB.62.8564.

[58] S. Plimpton, Fast Parallel Algorithms for Short-Range Molecular Dynamics, J. Comput. Phys. 117 (1995) 1-19. doi:10.1006/jcph.1995.1039.

[59] D.G. Sangiovanni, D. Edström, L. Hultman, I. Petrov, J.E. Greene, V. Chirita, Ti adatom diffusion on TiN(001): Ab initio and classical molecular dynamics simulations, Surf. Sci. 627 (2014) 34-41. doi:10.1016/j.susc.2014.04.007.

[60] D.G. Sangiovanni, D. Edström, L. Hultman, I. Petrov, J.E. Greene, V. Chirita, Ab initio and classical molecular dynamics simulations of $\mathrm{N}_{2}$ desorption from TiN(001) surfaces, Surf. Sci. 624 (2014) 25-31. doi:10.1016/j.susc.2014.01.007.

[61] J.A. Thornton, J.E. Greene, Sputter Deposition Processes, in: R.F. Bunshah (Ed.), Depos. Technol. Films Coat., Noyes Publications, Park Ridge, NJ, 1994: p. 249.

[62] W. Humphrey, A. Dalke, K. Schulten, VMD: Visual molecular dynamics, J. Mol. Graph. 14 (1996) 33-38. doi:10.1016/0263-7855(96)00018-5.

[63] D. Gall, S. Kodambaka, M.A. Wall, I. Petrov, J.E. Greene, Pathways of atomistic processes on TiN(001) and (111) surfaces during film growth: an ab initio study, J. Appl. Phys. 93 (2003) 9086. doi:10.1063/1.1567797. 


\section{Figure Captions}

Figure 1: Initial substrate, consisting of misoriented TiN grains, grown on $\operatorname{TiN}(001)$. Ti atoms are blue while $\mathrm{N}$ atoms are yellow. The dashed square in the upper right of the image shows a typical misoriented 111 grain. The dashed line within the square shows the cut along which the crosssectional views are obtained.

Figure 2: Number of Ti and $\mathrm{N}$ atoms (left) in the growing TiN film plotted vs film coverage $\theta$. The right vertical axis shows the corresponding N/Ti ratio.

Figure 3: (a) - (g) Evolution of the misoriented 111 TiN grain highlighted in Figure 1 during the initial deposition. Ti atoms are blue while $\mathrm{N}$ atoms are yellow. Each panel shows both a plan view and a cross-sectional view of the grain along the cut defined in Figure 1. The original misoriented grain is outlined in white in each cross-section. The boundary between 001 and 111 orientations is highlighted with a cyan line in images (a)-(c). (a) Prior to deposition, (b) $\theta=0.61 \mathrm{ML}$, (c) $\theta=0.82 \mathrm{ML}$, (d) $\theta=$ $1.13 \mathrm{ML}$, (e) $\theta=1.43 \mathrm{ML}$, (f) $\theta=1.43 \mathrm{ML}$ followed by $0.15 \mathrm{~ns}$ of relaxation, (g) $\theta=3.04 \mathrm{ML}$, (h) $\theta=$ $5.74 \mathrm{ML}$, and (i) $\theta=9.81 \mathrm{ML}$.

Figure 4: Fraction of non-epitaxial Ti atoms versus TiN film coverage $\theta$. 


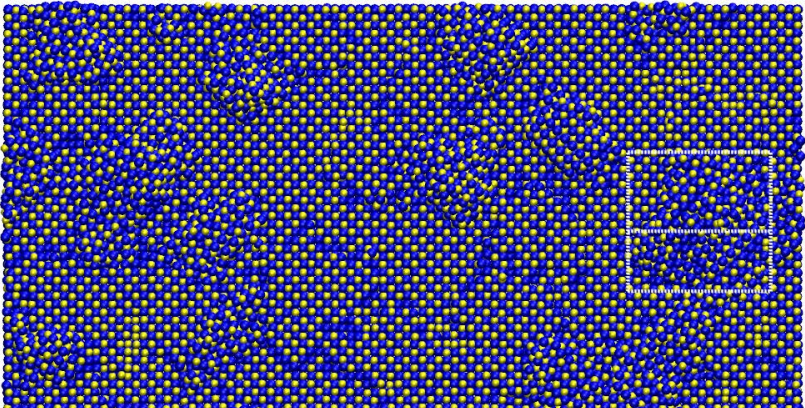


(a) 890

(n)

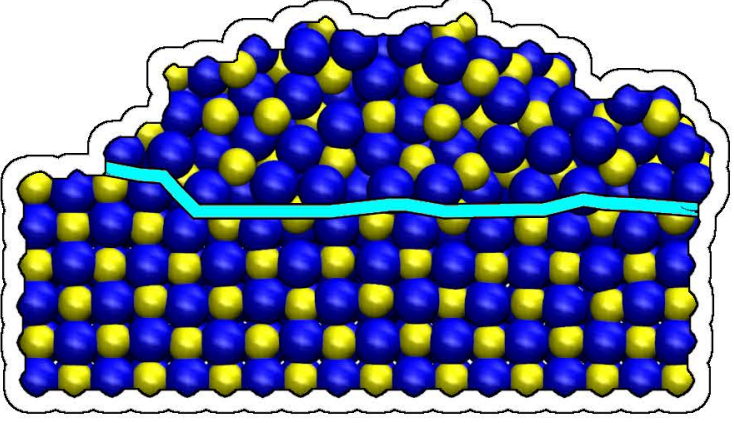

(d)

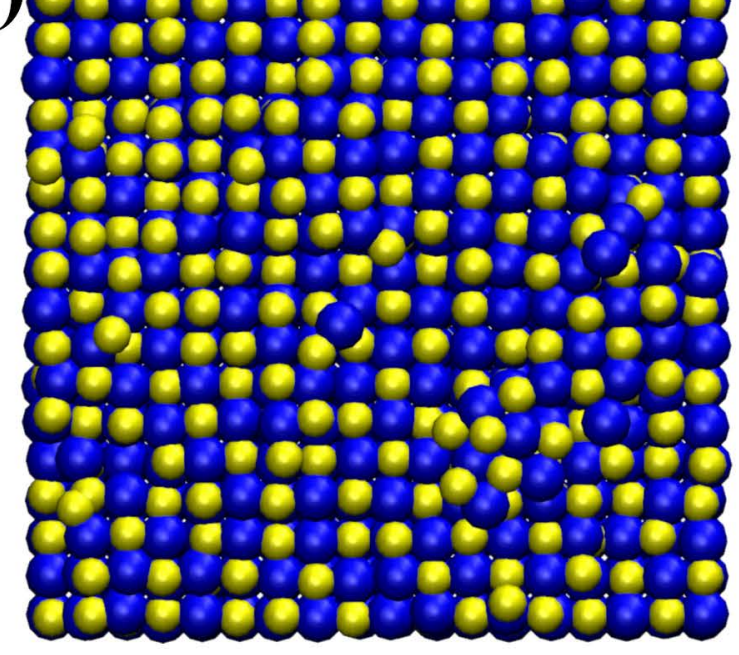

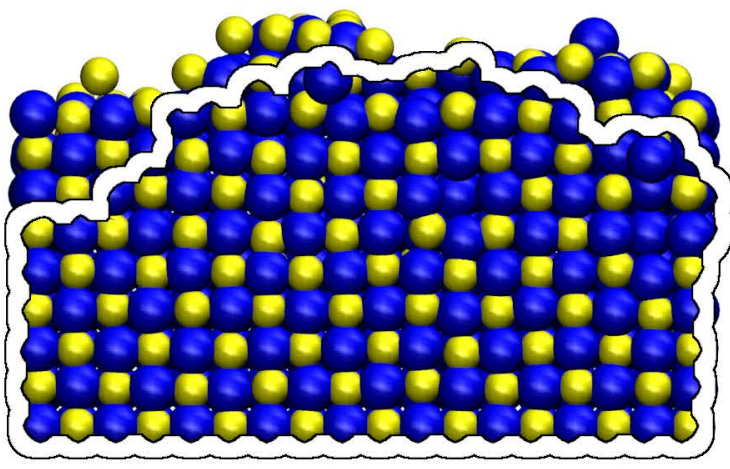

(g)
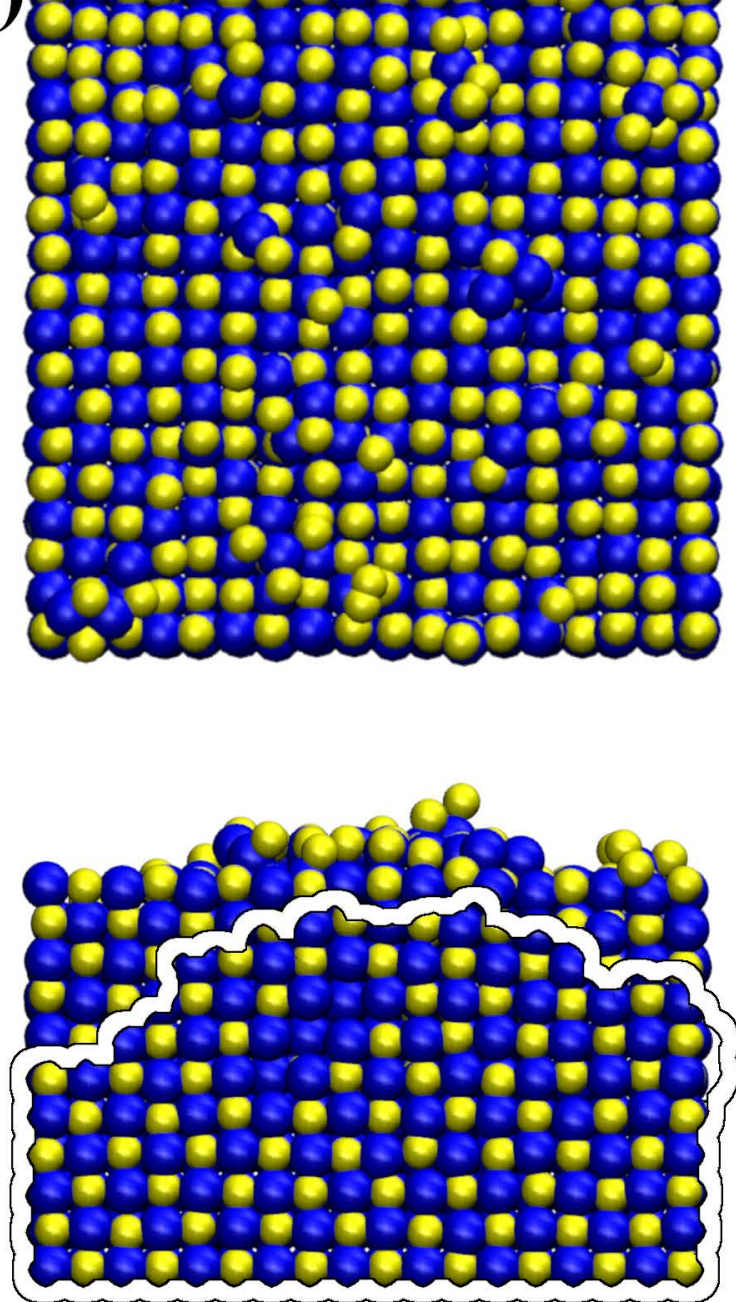

(b) 8998979989998

$89.98 \%$ 80909 $80900 \%$

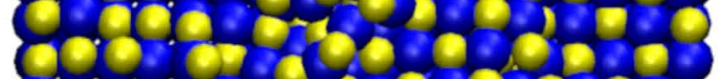
gntor. 809909.9896

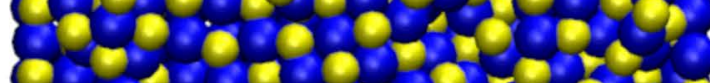

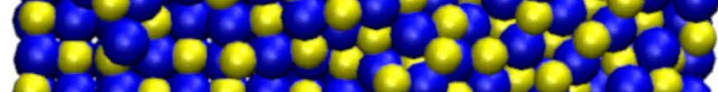
$809: 89.969$ 808000001968

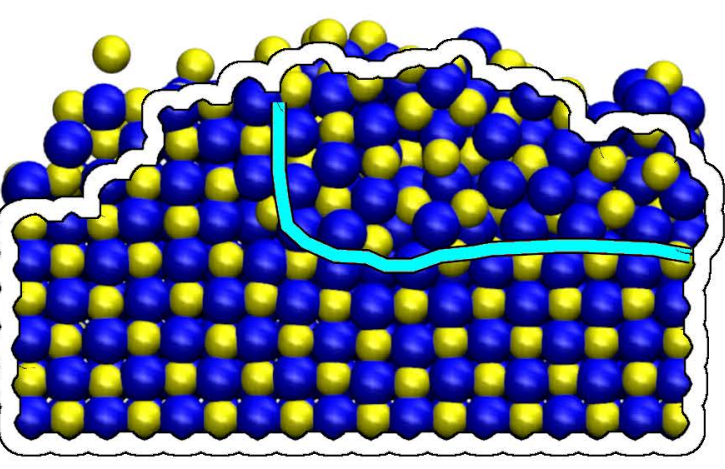

(e) 899099989095 8.969 .9 $0.090 .0 \%$ dacesos. 80196909003

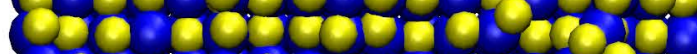
6.9. Co $08 \% 1.7$ 8089.99989

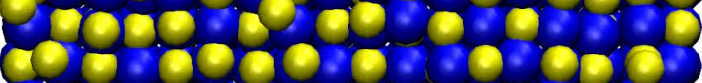
800000900000

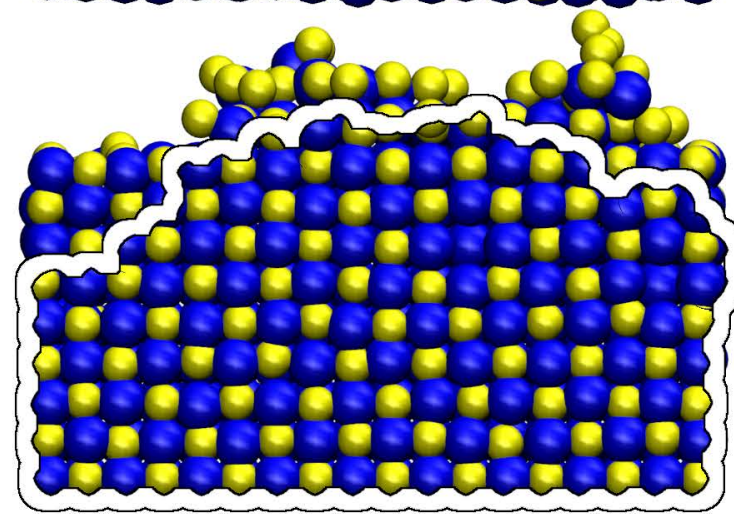

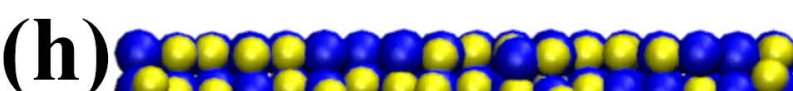

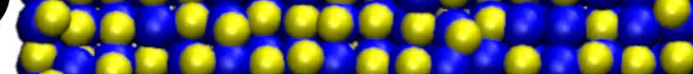

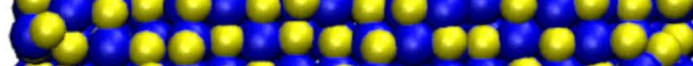
Q06.9. g. 90989.

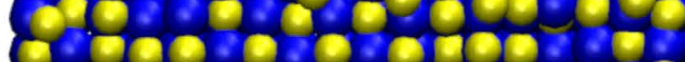

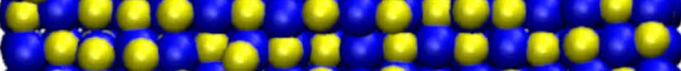

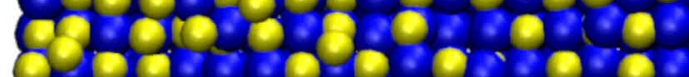

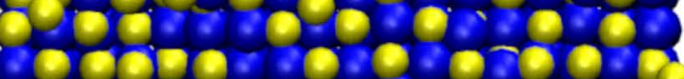
$89.9-7.4$ g.t. 0000 C.5.

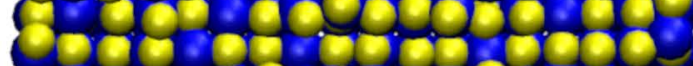
80000000

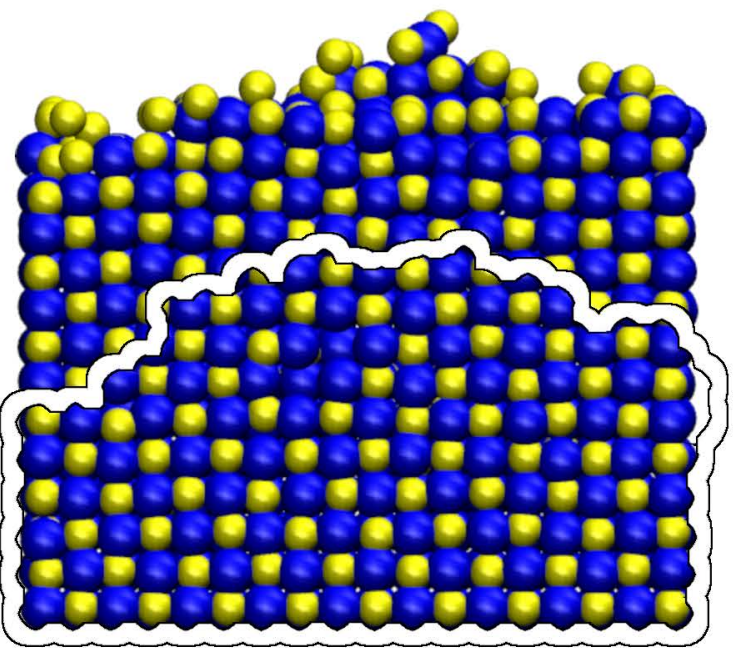

(c) 89896989658 80009090 E. $909 \%$ - 190982 Q 0.99 .910 8907909708 $00 \times 0.0909$ $8900 \% 90103$ 8.9.8.8.98\% 8000000000

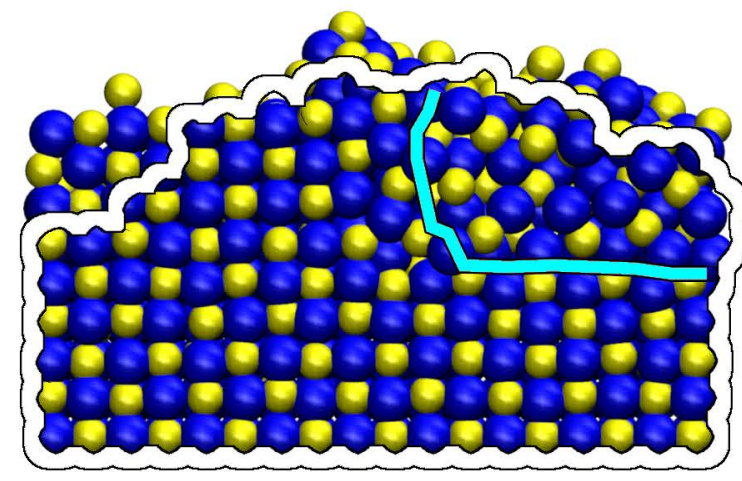

(f)

890998909 .

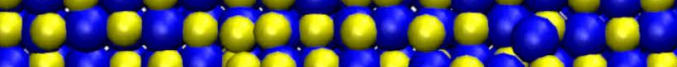

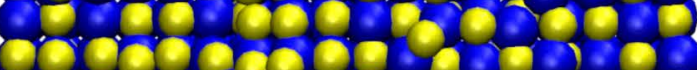

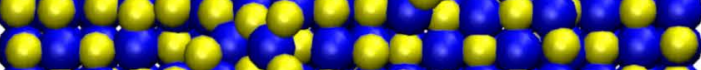

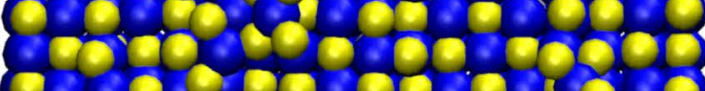

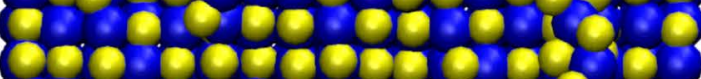

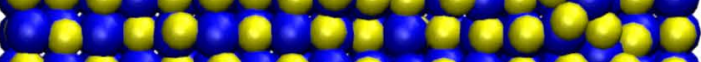

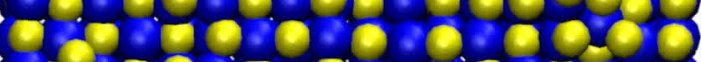

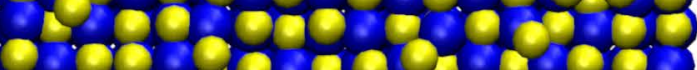
898009890989

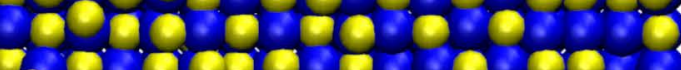

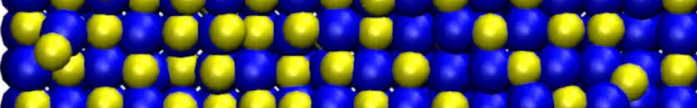
0.000000000

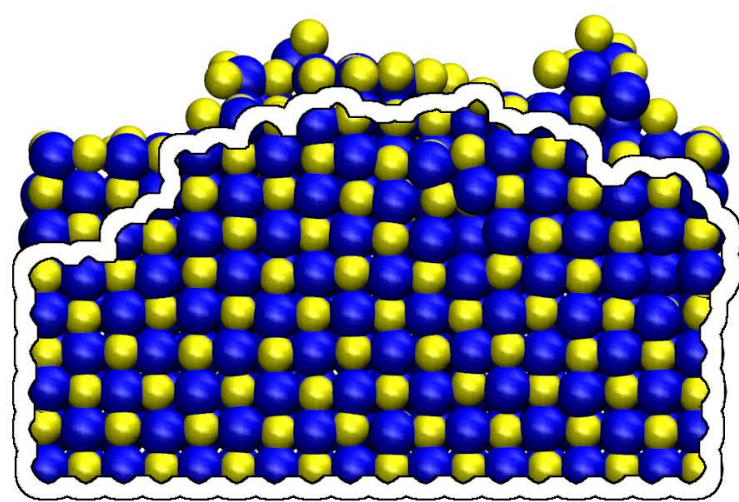

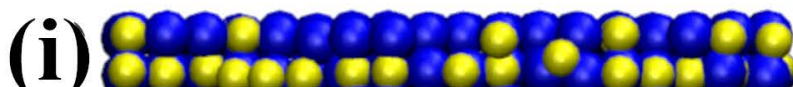

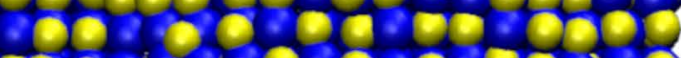
Ge.

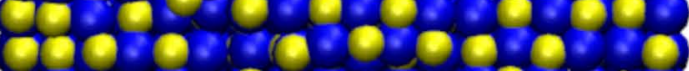
8.9.89:9:8:49:

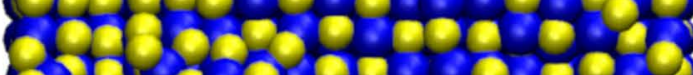

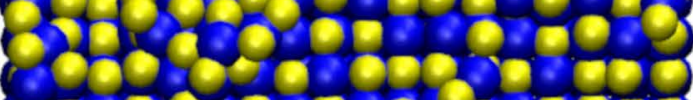

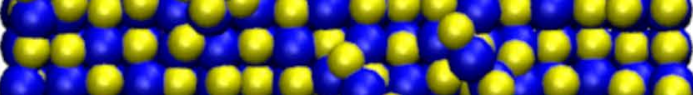

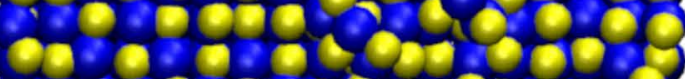
Q

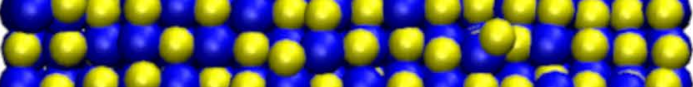

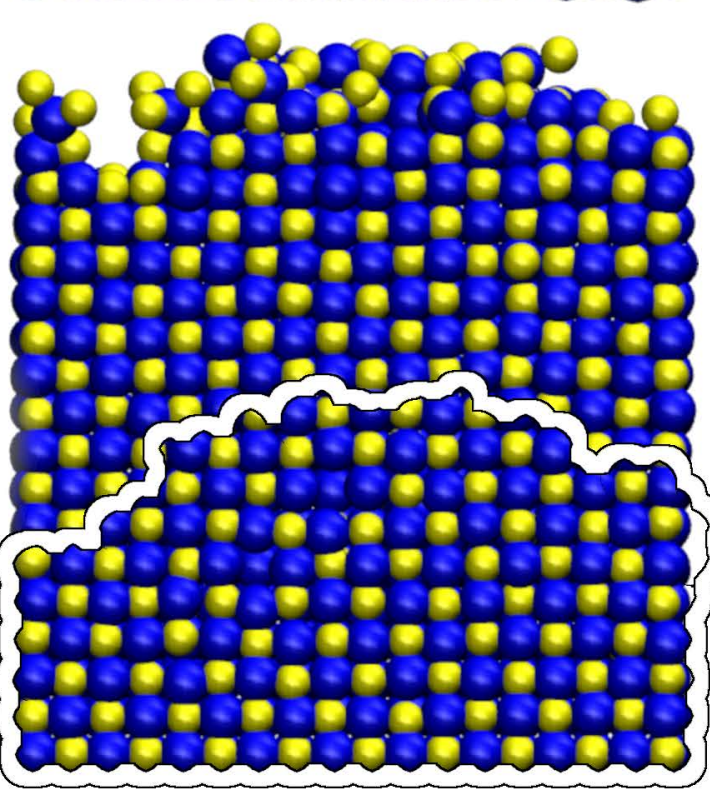


